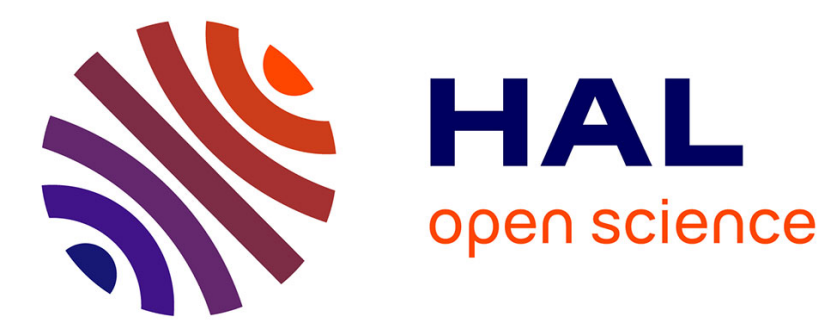

\title{
Sensory loss and suicide ideation in older adults: findings from the Three-City cohort study
}

S. Cosh, I. Carriere, V. Daien, C. Tzourio, C. Delcourt, C. Helmer

\section{To cite this version:}

S. Cosh, I. Carriere, V. Daien, C. Tzourio, C. Delcourt, et al.. Sensory loss and suicide ideation in older adults: findings from the Three-City cohort study. International Psychogeriatrics, In press, 10.1017/S104161021800056X . hal-01855921v2

\section{HAL Id: hal-01855921 \\ https://hal.science/hal-01855921v2}

Submitted on 27 Nov 2018

HAL is a multi-disciplinary open access archive for the deposit and dissemination of scientific research documents, whether they are published or not. The documents may come from teaching and research institutions in France or abroad, or from public or private research centers.
L'archive ouverte pluridisciplinaire HAL, est destinée au dépôt et à la diffusion de documents scientifiques de niveau recherche, publiés ou non, émanant des établissements d'enseignement et de recherche français ou étrangers, des laboratoires publics ou privés. 
Sensory Loss and Suicide Ideation in Older Adults: Findings from the ThreeCity cohort study

Authors: Dr Cosh $\mathrm{S}^{1,2} ¥$, Dr Carrière $1^{3,4}$, Dr Daien $\mathrm{V}^{3,4,5}$, Prof Tzourio $\mathrm{C}^{5,6}, \mathrm{Dr}$ Delcourt $C^{1}$, Dr Helmer $C^{1}$ and the Sense-Cog Group*.

${ }^{1}$ University of Bordeaux, Inserm, Bordeaux Population Health Research Center, team LEHA, UMR 1219, F-33000 Bordeaux, France

${ }^{2}$ University of New England, School of Behavioural, Cognitive and Social Sciences, Armidale, 2350, NSW, Australia

${ }^{3}$ Inserm U1061 Montpellier, F-34093, France

${ }^{4}$ University of Montpellier, Montpellier, F-34000, France

${ }^{5}$ Department of Ophthalmology, Gui De Chauliac Hospital, Montpellier, F-34000, France

6 Univ. Bordeaux, Inserm, Bordeaux Population Health Research Center, team HEALTHY, UMR1219, F-33000 Bordeaux, France

$¥$ Corresponding author

Université Bordeaux

Case 11146 rue Léo Saignat

33076 Bordeaux cedex

$\mathrm{Ph}:$ +33 557571393

Suzanne.cosh@adelaide.edu.au 
Objectives: To examine the longitudinal risk of vision or hearing loss for experiencing suicidal ideation in older adults.

Design: The Three-City study, examining data from three waves of follow-up (2006-2008; 2008-2010; 2010-2012).

Setting: Community dwelling older French adults.

Participants: $\mathrm{N}=5438$ adults aged 73 and over.

Measurements: Suicidality was assessed by the Mini International Neuropsychiatric Interview, Major Depressive Disorder module. Mild vision loss was defined as Parinaud of 3 or 4 and severe vision loss as Parinaud $>4$. Mild hearing loss was self-reported difficulty understanding a conversation and severe hearing loss as inability to understand a conversation.

Results: Severe vision loss was associated with increased risk of suicidal ideation at baseline $(\mathrm{OR}=1.59,95 \% \mathrm{Cls}=1.06-2.38)$ and over five years $(\mathrm{OR}=$ $1.65,95 \% \mathrm{Cls}=1.05-2.59)$. Mild and severe hearing loss were associated with increased risk of suicidal ideation, both at baseline $(\mathrm{OR}=1.29,95 \% \mathrm{Cls}=1.03-1.63$; $\mathrm{OR}=1.78,95 \% \mathrm{Cls}=1.32-2.40)$ and over five years $(\mathrm{OR}=1.47,95 \% \mathrm{Cls}=1.17-$ $1.85 ; \mathrm{OR}=1.97,95 \% \mathrm{Cls}=1.44-2.70)$.

Conclusion: Sensory losses in late life pose a risk for suicidal ideation. Suicidality requires better assessment and intervention in this population.

Key words: suicidal, elderly, vision impairment, dual sensory loss, hearing impairment, mental health

Running head: Sensory loss and suicide ideation in the elderly 


\section{Introduction}

Sensory losses are common globally amongst the elderly (WHO, 2012) leading to poorer mental health and reduced quality of life (Chia et al., 2006; Heine and Browning, 2014). Limitations in functional ability, resultant social isolation and inability to engage in pleasurable activities, as well as communication difficulties in $\mathrm{HL}$ are likely to impinge upon the wellbeing of older adults with sensory loss. Despite high rates of comorbid depression, and the well-established relationships between both VL and HL with depression (e.g., Carriere et al., 2013; Hsu et al., 2016), whether sensory losses are associated with the specific risk of suicidal ideation remains unclear. This is especially pertinent given that suicide in the elderly remains under-researched, despite older adults having comparatively high suicide rates globally (O'Connell et al., 2004). Furthermore, many commonly used depression screening tools do not assess suicidal ideation, thus older adults with sensory loss (including those with comorbid depression) may not be receiving adequate assessment and support.

Research examining suicide and suicidal behaviour in sensory loss is scant. An increased risk of suicide was reported in older adults with vision loss (Waern et al., 2002). Deaf adolescents have higher rates of suicidal behaviour (ideation, attempts) than the general population (Landsberger et al., 2014) and deaf adults commonly reported experiencing suicidal thoughts (Sheppard and Badger, 2010). However, only one population-based study to date has explored sensory loss and suicidal ideation. This cross-sectional analysis showed that older adults with sensory losses reported more suicidal ideation, although only vision loss (VL) significantly increased the risk (OR 1.43-1.65) (Kim et al., 2015). 
Research examining aspects of suicide in sensory loss remain limited, especially in older adults, with the majority of evidence relying on small samples; and longitudinal studies are lacking (Kim et al., 2015). The aim of the present study was to explore the risk of suicidal ideation in older adults with $V L$ or hearing loss $(\mathrm{HL})$ over 5 years.

\section{Methods}

This study forms part of the SENSE-Cog research programme, funded by European Union Horizon 2020 program (http://www.sense-cog.eu/), which aims to promote mental well-being in older adults with sensory and cognitive impairments (Cosh et al., forthcoming). SENSE-Cog is a multistage program including a) an epidemiology consortium to improve understanding of the complex inter-relationship of sensory impairments and cognitive and mental health functioning, b) development of appropriate screening tools and c) an intervention trial, in order to improve understanding, detection and treatment of multiple impairments amongst ageing adults. The current study forms part of the epidemiology project.

\section{Study sample}

Participants were from the Three-City (The 3C Study Group, 2003), a population-based cohort study of 9294 community-dwelling French adults aged 65 and over from three French cities (Bordeaux, Dijon and Montpellier). Baseline data were collected between 1999-2001, with regular follow ups conducted at 2-3 year intervals. This study analysed data from participants who completed the $4^{\text {th }}$ wave of follow-up (2006-2008), when suicidal ideation was assessed for the first time. Follow 
up data from the $5^{\text {th }}(2008-2010)$ and $6^{\text {th }}(2010-2012)$ waves are also analysed (length of follow-up $2.9 \pm 1.8$ years). Of the initial sample, $90.6 \%$ participated in at least one wave of follow-up, while $15.2 \%$ had died by the final follow up. The study protocol was approved by the Ethical Committees of the University-Hospitals of Bicêtre and Nîmes (France) and informed consent was obtained from participants. A detailed overview of the sampling and methodology of the $3 \mathrm{C}$ study has been published elsewhere (The 3C Study Group, 2003).

Measures

Suicide ideation: Suicide ideation was assessed via the suicidality item ('Did you repeatedly consider hurting yourself, feel suicidal, or wish that you were dead?') of the Major Depressive Disorder module of the Mini International Neuropsychiatric Interview (MINI) (Sheehan et al., 1998). Suicidal ideation was reassessed at 3 and 5 years $\left(5^{\text {th }}\right.$ and $6^{\text {th }}$ Waves of follow-up: reassessed at 3 years only in Bordeaux).

Sensory measures: Near visual acuity (presenting vision) was assessed with the Parinaud scale. Standardized cards were used at a reading distance of $33 \mathrm{~cm}$. Mild vision loss was classified as Parinaud of 3 or 4 (Snellen equivalent 20/30-20/60) and severe vision loss as Parinaud $>4$ (Snellen equivalent $<20 / 60$ ). Mild hearing loss was classified as self-reported difficulty understanding a conversation, and severe hearing loss was self-reported inability understanding a conversation. 
Covariates: Socio-demographic and health-related information was collected during interview; including education level (elementary schooling, secondary school, higher education), monthly income ( $<€ 760, € 760-2280,>€ 2280)$, marital status, living along or with others, alcohol consumption ( $<10,10-40,>40$ grams per day) and tobacco use (current-, past -, non-smoker). A composite score of functional ability was calculated based on scores from the Rosow-Breslau scale, the Lawton-Brody Instrumental Activities of Daily Living (IADL) scale and the Katz Index of basic ADL (autonomous, dependent in 2 or more areas of functioning; Barberger-Gateau et al., 2000). Cognitive functioning was assessed using the Mini-Mental State Examination (MMSE; <16, 16-23, 224). History of stroke, myocardial infarction, diabetes, and psychotropic medication use (ATC codes: N05A-C, N06A-B) as well as depression diagnosis (MINI) was obtained during medical interview. Blood pressure was measured using a digital electronic tensiometer OMRON M4. Hypertension was defined as $140 / 90 \mathrm{mmHg}$ or treatment with blood-pressure lowering drugs (ATC codes: C02, C03, C07, C08).

\section{Statistical Analysis}

Socio-demographic and health characteristics were compared according to sensory loss using chi-squares and one-way ANOVAs. The relationship between vision or hearing loss and suicidal ideation at baseline was examined using multivariate logistic regressions. The association between baseline sensory loss (Wave 4) and onset of suicidal ideation over follow-up (Waves 5 and 6) was examined amongst those who were free of suicidal ideation at baseline. The relationship with incident suicide ideation was examined using mixed logistic models, which take into account within-subject response correlation and model the individual 
repeated probabilities of the outcome during follow-up. Logistic mixed models are also robust to missing data, as well as the reversibility of outcome; thus capturing that suicidal ideation may be remit and/or recur over time and thus be present at 1 or more, but not all, time points. Potential interactions between vision and hearing, as well as between sensory loss and sex, income and education were examined. For each analysis, two models were undertaken; Model 1 adjusted for sex, study center, and age; Model 2 further adjusted for known covariates of mental wellbeing in older adults: education level, income, marital status, living alone, use of psychotropic medication, functional ability, hypertension, diabetes, smoking, alcohol consumption, depression, MMSE and history of stroke and myocardial infarction. Analyses were conducted using SAS 9.4 (SAS Institute, Inc., Cary, NC).

\section{Results}

5710 participants attended the $4^{\text {th }}$ follow-up, of whom $5438(95.2 \%)$ had sensory and MINI data. Mean age was $80.1(\mathrm{SD}=4.8)$ and the majority were female (62.9\%). 905 (16.6\%) had vision loss (mild=634; severe=271), while 2953 (54.3\%) reported hearing loss (mild=2019; severe=844). Those with sensory losses were older and in poorer physical health (Table 1). At baseline, 530 (9.7\%) participants reported presence of suicidal ideation and an additional 233 participants reported suicidal ideation over follow-up.

At baseline, mild and severe HL were associated with increased risk of suicide ideation, even after adjustment for potential confounders $(\mathrm{OR}=1.29,95 \%$ $\mathrm{Cls}=1.03-1.63 . \mathrm{p}=.03 ; \mathrm{OR}=1.78,95 \% \mathrm{Cls}=1.32-2.40, \mathrm{p}<.001$ respectively; Table 2). Mild VL was associated with increased risk in model 1, and this 
association remained close to significance after further adjustment (OR $=1.29,95 \%$ Cls $=0.97-1.73, p=.08)$. Severe VL was also significantly associated with increased risk of suicide ideation in both models $(\mathrm{OR}=1.59,95 \% \mathrm{Cls}=1.06-2.38 \mathrm{p}=.03)$.

Longitudinal analyses indicated that mild and severe HL predicted incident suicide ideation over 5 years (Waves 5 and 6$)$ of follow-up $(\mathrm{OR}=1.47,95 \% \mathrm{Cls}=$ 1.17-1.85, $p=.001 ; \mathrm{OR}=1.97,95 \% \mathrm{Cls}=1.44-2.70, \mathrm{p}<.001$, respectively). Severe VL was also associated with increased risk of suicidal ideation $(\mathrm{OR}=1.65,95 \% \mathrm{Cls}$ $=1.05-2.59, \mathrm{p}=.03$, ). Again mild VI was associated with increased risk in the partially adjusted model, and remained close to significance in the fully adjusted model $(\mathrm{OR}=1.30,95 \% \mathrm{Cls}=0.95-1.85, \mathrm{p}=.08)$. Odds ratios for $\mathrm{HL}$ and $\mathrm{VL}$ remained largely unchanged by adjustment for covariates. All examined interactions including those between VL and HL were non-significant.

\section{Discussion}

This study contributes to the limited literature examining aspects of suicide in sensory loss in older adults and highlighted that VL and HL were associated with increased risk of suicidal ideation cross-sectionally and over 5 years. Building on the documented relationships between $\mathrm{HL}$ and VL with depression, this study further highlights the specific additional risk posed to suicidal ideation in this population.

Associations between $\mathrm{HL}$ and suicide risk have been varied in prior studies, with VL but not HL associated with increased risk of suicidal ideation in a previous population-based study (Kim et al., 2015). Differences in findings may be explained by variations in HL assessment or by differences in populations studied, such as the older age of our population given that suicide rates increase with age in 
the elderly (O'Connell et al., 2004). Our findings further highlight that VL and HL are associated with increased risk for suicidal ideation over time, and risk increases with worsening severity of the loss. Concomitant with prior findings, only severe VL increased risk of suicide ideation (Waern et al., 2002). However, our findings also showed a trend toward significant for mild VI, suggesting that those at lower severity of VL may also have some vulnerability to suicide ideation.

Our results contribute to the currently limited literature regarding $\mathrm{HL}$ and mental health. Whether HL increases depression risk remains equivocal, especially over time (Gopinath et al., 2009; Hsu et al., 2016; Pronk et al., 2013) and longitudinal studies of mental wellbeing in $\mathrm{HL}$ are scant. Importantly, our findings suggest that $\mathrm{HL}$ may have a long-term impact on mental wellbeing.

The association between sensory losses and suicidal ideation might be explained by a number of pathways. Impaired functional ability resulting from the sensory loss increases reliance on others, which may increase perceptions of the self as a burden. Perceived burdensomeness is associated with greater suicidal ideation in the elderly (Cukrowicz et al., 2011). Loneliness is another strong predictor of suicidal behaviour (Stickley and Koyanagi, 2016) and is especially prominent in HL due to communication difficulties (Pronk et al., 2013). Whether the mechanisms underlying the relationship with suicide ideation are the same for $\mathrm{HL}$ and $\mathrm{VL}$ remains unclear and further study of the risk and mediating factors in each sensory loss is warranted.

These finding also build upon previous research that show longitudinal relationships between sensory loss and depression (Carriere et al., 2013; Kiely et al., 2013; McDonnall, 2009); further highlighting the crucial need for better 
understanding of this relationship and the mechanisms that might underlie these associations. Our findings further underscore the ongoing need to provide targeted intervention for older adults with sensory loss. Given that suicide ideation is not assessed in a range of commonly used depression screening tools, a specific focus on assessing suicide may be warranted and clinicians should be mindful of the need to specifically assess suicide ideation within these populations. Older adults with VL typically underutilise mental health care (van der Aa et al., 2015) and communication barriers impinge upon people with HL accessing mental health support (Sheppard and Badger, 2010); thus a renewed focus on assessment and targeted intervention for older adults with sensory loss appears needed. Ongoing research is needed to ascertain best practice for assessment and support of suicidality in these populations as well as to better promote access to mental health support.

Strengths of the present study included the sample size and longitudinal design. Weaknesses include that HL was self-reported. Thus self-reports may represent underestimates of actual $\mathrm{HL}$, due to many older adults perceiving hearing losses as natural elements of aging. Concomitantly, older adults with depression may be more likely to self-report HL. Although relationships remained significant after adjustment for cognitive functioning, the extent to which underlying cognitive decline and related difficulties understanding conversation, might have influence selfreport $\mathrm{HL}$ and the relationship with suicide ideation cannot be fully ascertained from our study. Moreover, the longer term effect of sensory loss on wellbeing cannot be gleaned given follow-up occurred over only 5 years. Ongoing assessment over longer term follow up and with measured $\mathrm{HL}$ would be invaluable in further understanding such relationships and in guiding provision of support to older adults. Additionally, suicide ideation was assessed by a single item, thus we were unable to 
explore the severity of suicidality or the association of sensory loss with other suicidal behaviours including suicide attempts. Whilst loneliness has been associated with HL long term (Pronk et al., 2013), which might crucially underlie the observed relationships with suicidal ideation, such data were not available in our study. Future research that better examines possible causal pathways would be beneficial.

Sensory losses increased the risk for suicidal ideation in older adults in both the short and long term. Given the increased rate of suicide in late life (O'Connell et al., 2004), suicidality amongst older adults with sensory loss requires better assessment, especially given the barriers to accessing mental health care worldwide for this population. 
Conflict of interest: none

Description of authors' roles: S Cosh was responsible for data analysis and manuscript preparation, I Carrière assisted with data analysis and interpretation of results, V Daien assisted with interpretation of results and writing the paper, $\mathrm{C}$ Tzourio was responsible for study design and overseeing data collection $C$ Delcourt assisted in designing the study, overseeing data collection and interpreting results, and $\mathrm{C}$ Helmer assisted with data analysis, interpretation and writing the paper.

\section{Acknowledgements:}

SENSE-Cog has received funding from the European Union's Horizon 2020 research and innovation programme under grant agreement No 668648.

The Three-City study is conducted under a partnership agreement between the Institut National de la Santé et de la Recherche Médicale (INSERM), the University Bordeaux 2 Victor Segalen and Sanofi-Aventis. The Fondation pour la Recherche Médicale funded the preparation and initiation of the study.

The Three-City study is also supported by the Caisse Nationale Maladie des Travailleurs Salariés, Direction Générale de la Santé, MGEN, Institut de la Longévité, Conseils Régionaux d'Aquitaine et Bourgogne, Fondation de France, Ministry of Research-INSERM Programme "Cohortes et collections de données biologiques", Agence Nationale de la Recherche ANR PNRA 2006 and LongVie 2007, and the "Fondation Plan Alzheimer" (FCS 2009-2012). 


\section{Reference List}

Barberger-Gateau, P., Rainville, C., Letenneur, L. and Dartigues, J. F. (2000). A hierarchical model of domains of disablement in the elderly: a longitudinal approach. Disabil Rehabil, 22, 308-317. Carriere, I., et al. (2013). A prospective study of the bi-directional association between vision loss and depression in the elderly. J Affect Disord, 151, 164-170.

Chia, E. M., Mitchell, P., Rochtchina, E., Foran, S., Golding, M. and Wang, J. J. (2006). Association between vision and hearing impairments and their combined effects on quality of life. Arch Ophthalmol, 124, 1465-1470.

Cukrowicz, K. C., Cheavens, J. S., Van Orden, K. A., Ragain, R. M. and Cook, R. L. (2011). Perceived burdensomeness and suicide ideation in older adults. Psychol Aging, 26, 331-338.

Gopinath, B., et al. (2009). Depressive symptoms in older adults with hearing impairments: the Blue Mountains Study. J Am Geriatr Soc, 57, 1306-1308.

Heine, C. and Browning, C. J. (2014). Mental health and dual sensory loss in older adults: a systematic review. Front Aging Neurosci, 6, 83.

Hsu, W. T., et al. (2016). Increased risk of depression in patients with acquired sensory hearing loss: A 12-year follow-up study. Medicine (Baltimore), 95, e5312.

Kiely, K. M., Anstey, K. J. and Luszcz, M. A. (2013). Dual sensory loss and depressive symptoms: the importance of hearing, daily functioning, and activity engagement. Front Hum Neurosci, 7, 837.

Kim, Y., Kwak, Y. and Kim, J. S. (2015). The association between suicide ideation and sensory impairment among elderly Koreans. Aging Ment Health, 19, 658-665.

Landsberger, S. A., Diaz, D. R., Spring, N. Z., Sheward, J. and Sculley, C. (2014). Psychiatric diagnoses and psychosocial needs of outpatient deaf children and adolescents. Child Psychiatry Hum Dev, 45,

42-51.

McDonnall, M. C. (2009). The effects of developing a dual sensory loss on depression in older adults: a longitudinal study. J Aging Health, 21, 1179-1199.

O'Connell, H., Chin, A.-V., Cunningham, C., Lawlor, B. A. and Norman, C. (2004). Recent developments: Suicide in older people. British Medical Journal, 329, 895-899.

Pronk, M., Deeg, D. J. and Kramer, S. E. (2013). Hearing status in older persons: a significant determinant of depression and loneliness? Results from the longitudinal aging study amsterdam. Am J Audiol, 22, 316-320.

Sheehan, D. V., et al. (1998). The Mini-International Neuropsychiatric Interview (M.I.N.I.): the development and validation of a structured diagnostic psychiatric interview for DSM-IV and ICD-10. J Clin Psychiatry, 59 Suppl 20, 22-33;quiz 34-57.

Sheppard, K. and Badger, T. (2010). The lived experience of depression among culturally Deaf adults. J Psychiatr Ment Health Nurs, 17, 783-789.

Stickley, A. and Koyanagi, A. (2016). Loneliness, common mental disorders and suicidal behavior: Findings from a general population survey. J Affect Disord, 197, 81-87.

The 3C Study Group (2003). Vascular factors and risk of dementia: design of the Three-City Study and baseline characteristics of the study population. Neuroepidemiology, 22, 316-325.

van der Aa, H. P., Hoeben, M., Rainey, L., van Rens, G. H., Vreeken, H. L. and van Nispen, R. M. (2015). Why visually impaired older adults often do not receive mental health services: the patient's perspective. Qual Life Res, 24, 969-978.

Waern, M., Rubenowitz, E., Runeson, B., Skoog, I., Wilhelmson, K. and Allebeck, P. (2002). Burden of illness and suicide in elderly people: case-control study. Bmj, 324, 1355.

WHO (2012). Mortality and budren of diseases. World Health Organisation 
Table 1: Characteristics of the study population by sensory loss at $4^{\text {th }}$ Wave. Three-City Study 2006-2008, N=5438

\begin{tabular}{|c|c|c|c|c|c|c|c|c|c|c|c|c|c|}
\hline \multirow[b]{2}{*}{ Age M(SD) } & \multicolumn{2}{|c|}{$\begin{array}{c}\text { No sensory loss } \\
n=2160\end{array}$} & \multicolumn{2}{|c|}{$\begin{array}{l}\text { Mild VL only } \\
\quad \mathrm{n}=236\end{array}$} & \multicolumn{2}{|c|}{$\begin{array}{c}\text { Severe VL only } \\
n=89\end{array}$} & \multicolumn{2}{|c|}{$\begin{array}{c}\text { Mild HL only } \\
n=1756\end{array}$} & \multicolumn{2}{|c|}{$\begin{array}{l}\text { Severe HL } \\
\text { only } n=617\end{array}$} & \multicolumn{2}{|c|}{$\begin{array}{c}\text { VL and } H L \\
n=580\end{array}$} & \multirow{2}{*}{$\begin{array}{c}\mathbf{p} \\
<.001\end{array}$} \\
\hline & 78.9 & $(4.2)$ & 81.0 & $(4.7)$ & 81.4 & $(4.8)$ & 79.7 & $(4.6)$ & 82.0 & $(5.2)$ & 83.3 & $(5.5)$ & \\
\hline Female N (\%) & 1481 & $(68.6)$ & 175 & $(74.2)$ & 61 & $(68.5)$ & 1000 & $(57.0)$ & 329 & (53.3) & 376 & (64.8) & $<.001$ \\
\hline Suicide ideation (baseline) & 164 & $(7.6)$ & 31 & $(13.1)$ & 13 & $(14.6)$ & 167 & $(9.5)$ & 70 & (11.3) & 85 & (14.7) & $<.001$ \\
\hline \multicolumn{14}{|l|}{ Education (reference category: high) } \\
\hline Low & 442 & $(20.5)$ & 72 & $(30.6)$ & 29 & $(32.6)$ & 359 & $(20.5)$ & 146 & $(23.7)$ & 172 & $(29.7)$ & $<.001$ \\
\hline Mid & 1265 & $(58.7)$ & 130 & (55.3) & 48 & (53.9) & 1000 & $(57.0)$ & 339 & $(55.0)$ & 322 & $(55.5)$ & .478 \\
\hline \multicolumn{14}{|l|}{ Income (reference category : high) } \\
\hline Mid (€760-2280) & 1172 & $(57.2)$ & 154 & (65.3) & 52 & $(58.4)$ & 964 & (54.9) & 315 & $(51.1)$ & 351 & $(65.1)$ & $<.001$ \\
\hline Married & 1322 & $(61.2)$ & 127 & (53.8) & 45 & $(50.6)$ & 1110 & (63.3) & 392 & (63.5) & 279 & $(48.2)$ & $<.001$ \\
\hline \multicolumn{14}{|c|}{ Smoking(reference category non-smoker) } \\
\hline Current smoker & 102 & $(4.7)$ & 16 & $(6.8)$ & 9 & $(10.1)$ & 102 & $(5.8)$ & 30 & $(4.9)$ & 22 & $(3.8)$ & .066 \\
\hline Past smoker & 629 & $(29.1)$ & 67 & $(28.4)$ & 23 & (25.8) & 615 & $(35.0)$ & 231 & $(37.4)$ & 186 & (32.1) & $<.001$ \\
\hline Psychotropic medication use & 482 & (22.3) & 78 & (33.1) & 30 & $(33.7)$ & 400 & $(22.8)$ & 175 & $(28.4)$ & 198 & $(34.1)$ & $<.001$ \\
\hline \multicolumn{14}{|c|}{ Alcohol consumption (reference category: high) } \\
\hline Low (<10 grams per/day) & 1286 & $(59.6)$ & 146 & $(61.9)$ & 61 & $(68.5)$ & 1012 & $(57.4)$ & 329 & $(53.3)$ & 357 & 61.55 & .009 \\
\hline Moderate (10-40g per/day) & 719 & $(34.9)$ & 68 & $(29.4)$ & 24 & $(28.2)$ & 585 & $(34.6)$ & 228 & $(38.5)$ & 182 & $(32.3)$ & .088 \\
\hline \multicolumn{14}{|c|}{ Functional ability (reference category: autonomous) } \\
\hline Mild & 666 & $(31.7)$ & 94 & $(40.9)$ & 35 & $(42.2)$ & 590 & $(34.6)$ & 232 & $(39.0)$ & 269 & $(48.1)$ & $<.001$ \\
\hline Moderate & 58 & $(2.8)$ & 21 & $(9.1)$ & 9 & $(10.1)$ & 67 & (3.9) & 40 & $(6.7)$ & 61 & $(10.9)$ & $<.001$ \\
\hline Severe & 5 & $(0.1)$ & 2 & $(0.9)$ & 1 & $(1.2)$ & 3 & $(0.2)$ & 0 & $(0.0)$ & 5 & $(0.9)$ & $<.001$ \\
\hline History of Myocardial infarction & 69 & $(3.2)$ & 17 & $(7.2)$ & 7 & $(7.9)$ & 71 & $(4.1)$ & 31 & $(5.0)$ & 26 & $(4.5)$ & .001 \\
\hline History of Stroke & 58 & $(2.7)$ & 7 & $(3.0)$ & 6 & $(6.8)$ & 51 & $(2.9)$ & 25 & $(4.1)$ & 27 & $(4.8)$ & .039 \\
\hline Diabetes & 199 & $(9.2)$ & 27 & (11.4) & 11 & (12.4) & 170 & $(9.7)$ & 76 & (12.4) & 76 & (13.2) & .079 \\
\hline MDD & 29 & $(1.3)$ & 4 & 1.7 & 2 & $(1.8)$ & 40 & (2.3) & 11 & $(1.8)$ & 12 & $(2.1)$ & .341 \\
\hline \multicolumn{14}{|l|}{ MMSE (reference $\geq 24$ ) } \\
\hline$<16$ & 134 & $(6.2)$ & 26 & $(11.0)$ & 13 & $(14.7)$ & 21 & $(1.2)$ & 13 & $(2.1)$ & 247 & $(42.6)$ & $<.001$ \\
\hline $16-23$ & 112 & $(5.2)$ & 24 & $(10.2)$ & 8 & $(9.0)$ & 51 & $(2.9)$ & 14 & $(2.3)$ & 149 & $(25.7)$ & $<.001$ \\
\hline
\end{tabular}

VL: Visual loss; HL: Hearing Loss; SD: Standard deviation, ${ }^{a}=$ determined by one-way ANOVA, all other $p$ values determine by Chi square tests 
Table 2: Association between sensory loss and suicidal ideation

\begin{tabular}{|c|c|c|c|c|c|c|c|c|}
\hline \multirow{2}{*}{$\begin{array}{l} \\
\text { Baseline }\end{array}$} & \multicolumn{4}{|c|}{ Model 1} & \multicolumn{4}{|c|}{ Model 2} \\
\hline & OR & \multicolumn{2}{|c|}{$95 \% \mathrm{Cl}$} & $\mathbf{p}$ & OR & \multicolumn{2}{|c|}{$95 \% \mathrm{Cl}$} & p \\
\hline Mild & 1.43 & 1.17 & 1.75 & .001 & 1.29 & 1.03 & 1.63 & .029 \\
\hline \multicolumn{9}{|l|}{ Hearing } \\
\hline \multicolumn{9}{|l|}{ Loss } \\
\hline Severe & 1.87 & 1.42 & 2.45 & $<.001$ & 1.78 & 1.32 & 2.40 & $<.001$ \\
\hline \multicolumn{9}{|l|}{ Hearing } \\
\hline \multicolumn{9}{|l|}{ Loss } \\
\hline Mild Visual & 1.40 & 1.08 & 1.82 & .011 & 1.29 & 0.97 & 1.73 & .081 \\
\hline \multicolumn{9}{|l|}{ Loss } \\
\hline Severe & 1.76 & 1.23 & 2.52 & .002 & 1.59 & 1.06 & 2.38 & .025 \\
\hline \multicolumn{9}{|l|}{ Visual Loss } \\
\hline \multicolumn{9}{|l|}{ Over 5} \\
\hline \multicolumn{9}{|l|}{ years } \\
\hline Mild & 1.53 & 1.24 & 1.90 & $<.001$ & 1.47 & 1.17 & 1.85 & .001 \\
\hline \multicolumn{9}{|l|}{ Hearing } \\
\hline \multicolumn{9}{|l|}{ Loss } \\
\hline Severe & 2.03 & 1.52 & 2.70 & $<.001$ & 1.97 & 1.44 & 2.70 & $<.001$ \\
\hline \multicolumn{9}{|l|}{ Hearing } \\
\hline \multicolumn{9}{|l|}{ Loss } \\
\hline Mild Visual & 1.53 & 1.15 & 2.02 & .003 & 1.30 & 0.95 & 1.85 & .075 \\
\hline \multicolumn{9}{|l|}{ Loss } \\
\hline Severe & 2.00 & 1.34 & 2.97 & $<.001$ & 1.65 & 1.05 & 2.59 & .031 \\
\hline Visual Loss & & & & & & & & \\
\hline
\end{tabular}

Model 1: baseline $\mathrm{N}=5438$, longitudinal $\mathrm{N}=4908$; adjusted for sex, age, center

Model 2: baseline $\mathrm{N}=4608$, longitudinal $\mathrm{N}=4074$; adjusted for sex, age, center, education, income, marital status, psychotropic medication use, functional ability, hypertension, diabetes, smoking, alcohol consumption, and history of stroke, depression, MMSE and myocardial infarction OR: odds ratio

$\mathrm{Cl}$ : confidence interval 


\section{Table legends}

Table 1: Characteristics of the study population by sensory loss at $4^{\text {th }}$ Wave. ThreeCity Study 2006-2008, N=5438 - shows that those with sensory losses were older and in poorer physical health on all assessed health factors except for diabetes than those without sensory loss

Table 2: Association between sensory loss and suicidal ideation - highlights that both hearing and vision loss were associated with increased risk of experiencing suicidal ideation both at baseline and over 5 years of follow-up

\section{Supplementary material}

1. Authorlist for Sense-Cog WP1 group 